\title{
ПСИХОЛОГИЧЕСКИЕ ОСОБЕННОСТИ ДЕСТРУКТИВНОГО ПОВЕДЕНИЯ У БОЛЬНЫХ ШИЗОФРЕНИЕЙ
}

\section{Актуальность}

Ш изофрения является одним из самых распространенных психических заболеваний в мире ${ }^{1}$. В структуре инвалидности по психическим заболеваниям практически половину составляют именно больные шизофренией ${ }^{2}$.

В настоящее время в исследованиях больных шизофренией недостаточно данных об особенностях функционирования личности при этом заболевании ${ }^{3}$. В психиатрических клиниках при изучении личности пациентов уделяется большее внимание преимущественно когнитивной сфере. В то же время недооценивается роль личностных переменных, тесно взаимодействующих с факторами социальной среды.
\end{abstract}

Аннотация. Статья посвящена исследованию психологических особенностей, обуславливающих деструктивное поведение при параноидной шизофрении. Как показало следование, в Эго-структуре личности больных преобладают такие Эго-функиии, как дефицитарная агрессия, деструктивная тревога, внеинее Эго-отграничение и нарииссизм. Анализ форм агрессивного поведения (по Buss и Durkey) показал, что в обследованной группе больных преобладают такие формы агрессии как подозрительность, вербальная агрессия и чувство виньы. Среди неосознаваемых тенденций и потребностей личности у больных шизофренией на первый план выходят такие потребности, как агрессия, самооправдание, избегание опасности, избегание неудач, понимание, отвержение. Выявленные особенности нуждаются в последующей психокоррекиионной и профилактической работе.

Ключевые слова: психология, агрессия, деструктивное поведение, неосознаваемые тенденции личности, предикторы агрессии, Эго-структура, проективные тесты, шизофрения, потребности, Hand-тест.

1 Bhugra D (2006). The global prevalence of schizophrenia. PLoS Medicine 2 (5): 372-373.

2 Левикова Е.В. Социальная компетентность больных шизофренией подростков. Часть 1 [Электронный ресурс]// Психологические исследования: электрон. науч. журн. 2010. № 2(10). URL: http://psystudy.ru.

3 Мишанова А.В., Антохин Е.Ю., Матюшков С.В., Смирнова С.А., Костенецкая Н.В., Суходолов В.С. Структура перфекционизма больных, длительно страдающих шизофренией // Научно-медицинский вестник Центрального Черноземья. № 39 (3). Воронеж, 2010. С. 1-8.
Так, для больных шизофренией характерны нарушения различных сфер социального взаимодействия, проявляющиеся в семейных взаимоотношениях, конфликтах с коллегами по работе, что зачастую приводит к социальной изоляции ${ }^{4}$ У больных снижается способность к распознаванию эмоций другого человека, адекватному выражению собственных эмоций, к точной передаче полученной ими вербальной информации, вербальному выражению собственных чувств и мыслей. Больные шизофренией проявляют повышенную тревогу по отношению к социальным эмоционально значимым стимулам, их деятельность легко дезорганизуется под влиянием эмоциональных нагрузок 5 .

Важное значение имеет разработка проблемы социальных межличностных взаимосвязей при изучении расстройств шизофренического спектра ${ }^{6}$. Большин-

\footnotetext{
4 Лоскутова В.А. Социально-когнитивные функции при шизофрении и способы терапевтического воздействия // Социальная и клиническая психиатрия. 2009. Т. 19. № 4.

5 Холмогорова А.Б., Гараньян А.Г., Данлыкова А.А., Шмуклер А.Б. Программа тренинга когнитивных и социальных навыков (ТКСН) у больных шизофренией // Социальная и клиническая психиатрия. 2007. Т. 17. № 4.

6 Казьмина О.Ю. Структурно-динамические особенности систем межличностных взаимодействий у больных юноше-
} 


\section{Клиническая психология}

ство проблем, возникающих у больных шизофренией на начальном этапе заболевания, носят социальнопсихологический характер ${ }^{7}$. Частым спутником заболевания является снижение уровня побуждений и психической активности, нарушения в мотивационной сфере и самосознании, нарушения межличностного взаимодействия и социальной регуляции поведения 8 . Эти нарушения также являются одной из причин нарушений социального поведения у больных шизофренией. Таким образом, начавшееся заболевание при неблагоприятных обстоятельствах может приводить к быстрой социальной дезадаптации и инвалидизации больных

Что же представляет собой процесс межличностного взаимодействия в норме и патологии? Условно здоровые люди обычно выстраивают стратегию взаимодействия с окружающими людьми, исходя из актуальной ситуации, основываясь на восприятии поведенческих и эмоциональных реакций других людей и действуя в соответствии с собственными целями, интересами, ценностями и т.д. У больных шизофренией нарушение процесса межличностного взаимодействия обусловлено, во-первых, острым психотическим приступом, в ходе которого восприятие окружающей действительности грубо искажается, у больных утрачивается критика к своим поступкам, понимание их последствий; во-вторых, редукцией энергетического потенциала, в результате чего происходит снижение уровня побуждений и психической активности, личность тяготится социальными контактами, перестает активно интересоваться происходящими событиями в ближайшем социокультурном пространстве; в-третьих, изменениями в эмоциональном интеллекте в виде снижения или полного отсутствия способности распознавать и правильно оценивать эмоциональные реакции и переживания других людей; в-четвертых, нарушенной способностью к целеполаганию, построению четко продуманного плана действий на основе адекватной оценки ситуации.

ской малопрогредиентной шизофренией: автореф. дис. на соиск. уч. ст. ... канд. психологических наук. М., 1997.

7 См.: Лурия А.Р. Об исторической природе психических процессов. М., 1974. 215 с.; Ротштейн Г.А. Ипохондрическая шизофрения. М., 1961. 136 с.; Шорохова Е.В., Бобнева М.И. Проблемы изучения механизмов регуляции различных видов социального поведения // Психологические механизмы регуляции социального поведения / под ред. М.И. Бобневой и Е.В. Шороховой. М., 1979. 182 с.

8 См.:ЛеонтьевА.А.Психологияобщения. Тарту, 1974.196с.; Шостакович В.В., Блохина В.П., Белявский Н.Н. Критерий ранней диагностики шизофрении. Методическое письмо. Днепропетровск, 1972. 25 с.
В результате этих изменений, обусловленных патологическим процессом и, отчасти, стигматизацией психически больных людей в современном обществе, личность больного человека нередко прибегает к использованию неадаптивных моделей поведения, многие из которых разрушают процесс межличностного общения, носят агрессивный и даже антисоциальный характер, что приводит к еще большей изоляции больного от окружающих, к снижению психической активности, к избеганию социальных контактов. Выработка адаптивных стратегий поведения на основе когнитивно-поведенческой терапии, ориентированной на коррекцию ригидных когнитивных установок, позволило бы больным шизофренией более эффективно проходить процесс социальной реабилитации.

Теоретико-методологической основой исследования послужили базовые положения концепции Г.Аммона об Эго-функциях личности, которые условно можно разделить на конструктивные, деструктивные и дефицитарные. Согласно этой теоретической модели, каждый человек имеет конструктивные, деструктивные и дефицитарные структурные задатки, которые имеют различную индивидуально специфическую выраженность. Аммон считал, что эти структурные компоненты личности носят преимущественно неосознанный характер и находят свое выражение в установках и моделях поведения. Основной гипотезой исследования стало предположение о том, что поведенческие модели больных шизофренией, а также личностные предикторы, лежащие в их основе, носят преимущественно деструктивный и дефицитарный характер, а психотерапевтическая и психокоррекционная работа с больными, прежде всего, должна быть направлена на развитие конструктивных тенденций и стратегий поведения.

Теоретико-методологической базой исследования также выступили представления К. Хорни о стратегиях межличностного взаимодействия, среди которых она выделила ориентацию на людей (moving toward people), ориентацию против пюдей (moving against people) и ориентацию от людей (moving away from people) 9 .

Исследование проводилось на базе Оренбургской областной клинической психиатрической больницы №1. Было протестировано 40 пациентов с диагнозом параноидная шизофрения. В тестируемую выборку вошло 18 мужчин и 22 женщины в возрасте от 18 до 42 лет. Пациенты обследовались по выходу из острого психотического состояния, на 10-20 день пребывания в стационаре.

9 Хорни К. Наши внутренние конфликты. Конструктивная теория невроза / пер. с англ. В. Светлова. М.: Академический Проект, 2007. 224 c. 


\section{Психология и психотехника 3(54) • 2013}

\section{Эго-структура личности у больных шизофренией}

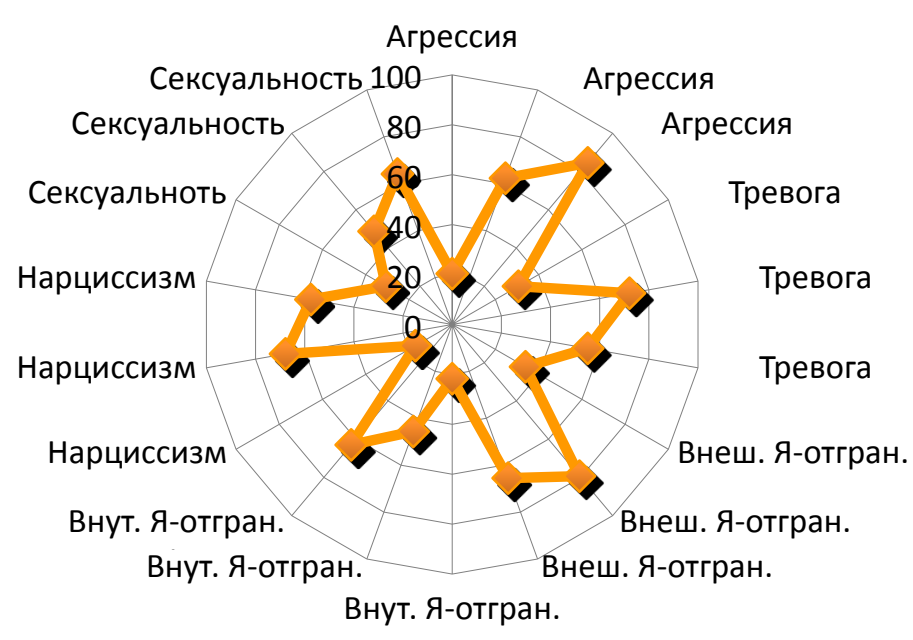

При работе с пациентами использовались методики: Я-структурный тест Г. Аммона, опросник БассаДарки, тематический апперцептивный тест, Hand-тест.

\section{Результаты}

Анализ базисных Эго-функций (в концепции Г. Аммона) показал, что в группе больных шизофренией преобладают следующие функции (рис. 1): агрессия дефицитарная, деструктивные тревога, внешнее Эгоотграничение и нарциссизм. Дефицитарная агрессия характеризуется отсутствием у пациентов активности, контакта с самими собой и другими людьми, пассивностью, уходом в себя, безучастностью, душевной пустотой. Подобные проявления четко коррелируют с негативной симптоматикой при шизофрении. Деструктивная тревога характеризуется переполняющим психику страхом, как бы парализующим поведение и общение. Для больных с преобладанием деструктивного внешнего Эго-отграничения характерна ригидная закрытость относительно чувств и интересов окружающих, отсутствие эмоционального участия, готовности к компромиссу, безэмоциональность и самоизоляция. Деструктивный нарциссизм характеризуется нереалистической самооценкой, уходом в свой внутренний мир, неспособностью принимать критику и эмоциональную поддержку окружающих.

При исследовании пациентов с помощью методики Басса-Дарки было выявлено среднее арифметическое индекса агрессивности для выборки - 15,5. Высокие значения индекса встречаются в группе больных лишь в 5\% случаев. Средний показатель индекса враждебности -
9,7. У 36 испытуемых этот показатель выше нормы, что свидетельствует о высоком уровне личностной враждебности при шизофрении.

По результатам опросника Басса-Дарки было обнаружено, что в обследованной группе преобладают такие формы агрессии как: подозрительность, вербальная агрессия и чувство вины. Преобладающие формы агрессивного поведения в группе больных шизофренией представлены в таблице 1.

Таблииа 1

\section{Формы агрессивного поведения у больных шизофренией}

\begin{tabular}{|c|c|}
\hline Форма агрессии & Среднее арифметическое \\
\hline Физическая агрессия & 4,7 \\
\hline Косвенная агрессия & 3,95 \\
\hline Вербальная агрессия & 6,18 \\
\hline Подозрительность & 5,18 \\
\hline Негативизм & 2,18 \\
\hline Раздражительность & 4,95 \\
\hline Обида & 4 \\
\hline Чувство вины & 5,78 \\
\hline
\end{tabular}

Высокие значения по шкале подозрительности свидетельствуют о недоверии, об осторожности пациентов по отношению к окружающим, об убежденности 
Клиническая психология

Puc. 2

\begin{abstract}
Средняя частота доминирующих потребностей (по Мюррею), представленных в рассказах ТАТ больных шизофренией
\end{abstract}

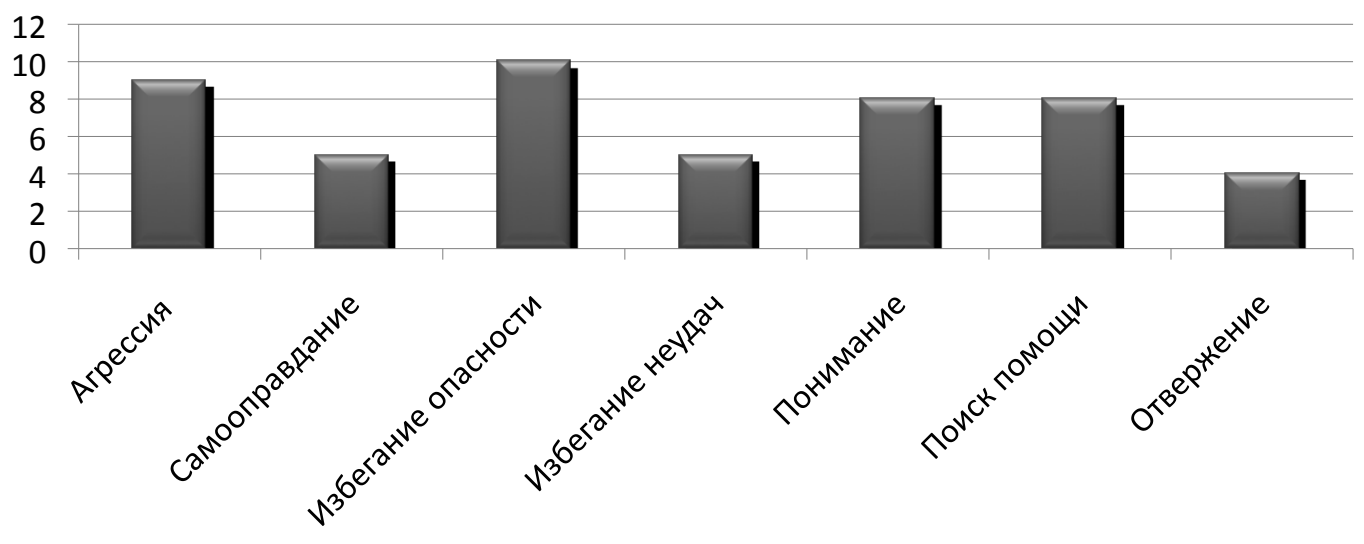

их в том, что другие люди планируют и приносят вред. Подобная картина вполне объясняется симптоматикой параноидной формы шизофрении. Высокие значения по шкале вербальной агрессии свидетельствуют о том, что пациенты склонны прибегать в конфликтных ситуациях к словесным угрозам. Чувство вины выражает убеждение больных в том, что они являются плохими людьми, что поступают зло. Данная шкала также демонстрирует ощущаемые пациентами угрызения совести за совершенные поступки или намерения. Таким образом, чувство вины в определенной мере представляет собой проявление аутоагрессии, обуславливающей у пациентов ощущение эмоционального дискомфорта.

Далее был проведен анализ личностных предикторов деструктивного поведения с помощью проективной методики ТАТ (тематический апперцептивный тест). Поскольку через характеристику главного героя рассказа и описание его действий испытуемый, по мнению авторов теста, сознательно или неосознанно использует некоторые фрагменты собственного прошлого или представляет свою личность, вполне вероятно, что данные, полученные с помощью этого метода, могут быть использованы при составлении набора внутриличностных факторов, формирующих поведение обследованных пациентов. Эти факторы - обозначим их «тенденции личности» - играют значительную роль в создании и последующей реализации определенной модели поведения.

При интерпретации рассказов пациентов за основу была взята техника "потребность-пресс» (Murray's system of needs), предложенная одним из создателей метода ТАТ - Г. Мюрреем. Согласно этой технике, каждое предложение испытуемого анализируется с точки зрения потребностей главного героя и внешних сил (прессов), воздействию которых он подвергается. Мюррей выделил 20 таких потребностей, представляющих собой, скорее, личностные тенденции, склонности к определенным действиям: уничижение, достижение, аффилиация, агрессия, автономия, преодоление трудностей, повиновение, самооправдание, доминирование, демонстративность, избегание опасности, избегание неудачи, опека, порядок, игра, отвержение, чувственность, секс, поиск помощи, понимание.

Согласно полученным результатам, в группе больных шизофренией преобладают следующие потребности (рис. 2): агрессия, самооправдание, избегание опасности, избегание неудач, понимание, отвержение. Следует отметить, что на первый план у больных шизофренией в системе потребностей выходят избегание опасности и агрессия, тесно связанная с враждебными чертами личности пациентов. При шизофрении отмечается качественная специфика враждебности и агрессивности, выражающаяся в подозрительности, настороженности, амбивалентности, экстрапунитивности и генерализации враждебного отношения ${ }^{10}$.

Далее с помощью методики Hand-тест было получено среднее значение индекса агрессивности в выборке $(1,8)$. В $62,5 \%$ случаев обнаружены высокие значения указанного индекса. Коэффициент ожидаемой агрессии - 5,84. Также у больных шизофренией выявлен низкий уровень общей психологической активности $(10,93)$.

10 Кузнецова О.О. Психологические особенности враждебности при психической патологии (шизофрении, шизоаффективном и аффективном расстройствах): Автореф. дис. на соиск. уч. ст. ... канд. психологических наук. М., 2007. 22 с. 


\section{Психология и психотехника 3(54) • 2013}

Анализ соотношения отдельных категорий ответов пациентов показал, что в группе больных преобладают ответы из категорий агрессивность (16\%), директивность $(10,6 \%)$, зависимость $(15,33 \%)$ и активные безличные ответы (30,13\%) (табл. 2).

Высокий коэффициент ожидаемой агрессии $(5,84)$ может свидетельствовать о том, что у больных шизофренией превалирует истинно агрессивное поведение ${ }^{11}$.

Преобладание у пациентов ответов на карточки теста, относящихся к таким категориям как агрессивность, директивность и активные безличные ответы, говорит о высокой вероятности проявления агрессии, о склонности испытуемых к активным действиям, к доминированию.

Таблииа 2

\section{Преобладающие категории ответов на стимульный материал Hand-теста в группе больных шизофренией}

\begin{tabular}{|c|c|}
\hline Название & $\begin{array}{c}\text { Доля от общего } \\
\text { количества } \\
\text { ответов (в \%) }\end{array}$ \\
\hline Агрессия & 16 \\
\hline Директивность & 10,6 \\
\hline Зависимость & 15,4 \\
\hline Активные безличные ответы & 30,1 \\
\hline
\end{tabular}

\section{Bиводы}

Анализ Эго-структуры личности показал, что для больных шизофренией более всего свойственны дефицитарные и деструктивные предикторы поведения. Преобладающими являются такие Эго-функции, как дефицитарная агрессия, деструктивные тревога, внешнее Эго-отграничение и нарциссизм.

Определен актуальный уровень агрессии у больных параноидной шизофренией и выявлены преобладающие формы деструктивного (агрессивного) поведения. К этим формам следует отнести подозрительность, вербальную агрессию и чувство вины.

Также для больных шизофренией, по результатам анализа рассказов ТАТ, характерно преобладание таких потребностей-тенденций, как агрессия, самооправдание, избегание опасности, избегание неудач, понимание (сбор информации), отвержение.

Проективное исследование личности пациентов с помощью Hand-теста позволило обнаружить неосознаваемые тенденции-предикторы, которые могут способствовать возникновению деструктивного поведения.

Таким образом, выявленные в ходе исследования психологические особенности личности больных шизофренией нуждаются не только в дальнейшем изучении их связи с личностными свойствами этих пациентов, но и в последующей коррекционной и профилактической работе, направленной на снижение вероятности возникновения и реализации деструктивных форм поведения.

\section{Список литературь:}

1. Казьмина О.Ю. Структурно-динамические особенности систем межличностных взаимодействий у больных юношеской малопрогредиентной шизофренией: автореф. дис. на соиск. уч. ст. ... канд. психологических наук. М., 1997.

2. Кузнецова О.О. Психологические особенности враждебности при психической патологии (шизофрении, шизоаффективном и аффективном расстройствах). Автореферат диссертации на соискание ученой степени кандидата психологических наук. М., 2007. 22 с.

3. Курбатова Т.Н., Муляр О.И. Проективная методика исследования личности «Наnd-тест». Методическое руководство. СПб.: ГМНППП «ИМАТОН», 2001.

4. Левикова Е.В. Социальная компетентность больных шизофренией подростков. Часть 1 [Электронный ресурс] // Психологические исследования: электрон. науч. журн. 2010. № 2(10). URL: http://psystudy.ru.

5. Леонтьев А.А. Психология общения. Тарту, 1974. 196 с.

6. Лоскутова В.А. Социально-когнитивные функции при шизофрении и способы терапевтического воздействия // Социальная и клиническая психиатрия. 2009. Т. 19. № 4.

7. Лурия А.Р. Об исторической природе психических процессов. М., 1974. 215 с.

11 Шостакович В.В., Блохина В.П., Белявский Н.Н. Критерий ранней диагностики шизофрении. Методическое письмо. Днепропетровск, 1972. 25 с. 


\section{Клиническая психология}

8. Мишанова А.В., Антохин Е.Ю., Матюшков С.В., Смирнова С.А., Костенецкая Н.В., Суходолов В.С. Структура перфекционизма больных, длительно страдающих шизофренией // Научно-медицинский вестник Центрального Черноземья. № 39 (3). Воронеж, 2010. С. 1-8.

9. Ротштейн Г.А. Ипохондрическая шизофрения. М., 1961. 136 с.

10. Холмогорова А.Б., Гараньян А.Г., Данлыкова А.А., Шмуклер А.Б. Программа тренинга когнитивных и социальных навыков (ТКСН) у больных шизофренией // Социальная и клиническая психиатрия. 2007. Т. 17. № 4.

11. Хорни К. Наши внутренние конфликты. Конструктивная теория невроза / пер. с англ. В. Светлова. М.: Академический Проект, 2007. 224 с.

12. Шорохова Е.В., Бобнева М.И. Проблемы изучения механизмов регуляции различных видов социального поведения // Психологические механизмы регуляции социального поведения / под ред. М.И. Бобневой и Е.В. Шороховой. М., 1979. 182 с.

13. Шостакович В.В., Блохина В.П., Белявский Н.Н. Критерий ранней диагностики шизофрении. Методическое письмо. Днепропетровск, 1972. 25 с.

14. Bhugra D (2006). The global prevalence of schizophrenia. PLoS Medicine 2 (5): 372-373.

\section{References (transliteration):}

1. Kaz’mina O.Yu. Strukturno-dinamicheskie osobennosti sistem mezhlichnostnykh vzaimodeystviy u bol'nykh yunosheskoy maloprogredientnoy shizofreniey. Avtoreferat dissertatsii na soiskanie uchenoy stepeni kandidata psikhologicheskikh nauk. M., 1997.

2. Kuznetsova O.O. Psikhologicheskie osobennosti vrazhdebnosti pri psikhicheskoy patologii (shizofrenii, shizoaffektivnom i affektivnom rasstroystvakh). Avtoreferat dissertatsii na soiskanie uchenoy stepeni kandidata psikhologicheskikh nauk. M., 2007. 22 s.

3. Kurbatova T.N., Mulyar O.I. Proektivnaya metodika issledovaniya lichnosti «Hand-test». Metodicheskoe rukovodstvo. SPb: GMNPPP «IMATON», 2001.

4. Levikova E.V. Sotsial'naya kompetentnost' bol'nykh shizofreniey podrostkov. Chast' 1 [Elektronnyy resurs] // Psikhologicheskie issledovaniya: elektron. nauch. zhurn. 2010. № 2(10). URL: http://psystudy.ru.

5. Leont'ev A.A. Psikhologiya obshcheniya. Tartu, 1974. $196 \mathrm{~s}$.

6. Loskutova V.A. Sotsial'no-kognitivnye funktsii pri shizofrenii i sposoby terapevticheskogo vozdeystviya // Sotsial'naya i klinicheskaya psikhiatriya. 2009. T. 19. № 4.

7. Luriya A.R. Ob istoricheskoy prirode psikhicheskikh protsessov. M., 1974. 215 s.

8. Mishanova A.V., Antokhin E.Yu., Matyushkov S.V., Smirnova S.A., Kostenetskaya N.V., Sukhodolov V.S. Struktura perfektsionizma bol'nykh, dlitel'no stradayushchikh shizofreniey // Nauchno-meditsinskiy vestnik Tsentral'nogo Chernozem’ya. № 39 (3). Voronezh, 2010. S. 1-8.

9. Rotshteyn G.A. Ipokhondricheskaya shizofreniya. M., 1961. $136 \mathrm{~s}$

10. Kholmogorova A.B., Garan'yan A.G., Danlykova A.A., Shmukler A.B. Programma treninga kognitivnykh i sotsial'nykh navykov (TKSN) u bol'nykh shizofreniey //Sotsial'naya i klinicheskaya psikhiatriya. 2007. T. 17. № 4.

11. Khorni K. Nashi vnutrennie konflikty. Konstruktivnaya teoriya nevroza / per. s angl. V. Svetlova. M.: Akademicheskiy Proekt, 2007. 224 s.

12. Shorokhova E.V., Bobneva M.I. Problemy izucheniya mekhanizmov regulyatsii razlichnykh vidov sotsial'nogo povedeniya // Psikhologicheskie mekhanizmy regulyatsii sotsial'nogo povedeniya / pod red. M.I. Bobnevoy i E.V. Shorokhovoy. M., 1979. 182 s.

13. Shostakovich V.V., Blokhina V.P., Belyavskiy N.N. Kriteriy ranney diagnostiki shizofrenii. Metodicheskoe pis'mo. Dnepropetrovsk, $1972.25 \mathrm{~s}$.

14. Bhugra D (2006). The global prevalence of schizophrenia. PLoS Medicine 2 (5): 372-373. 